\title{
Joint Optimal Production Control/Preventive Maintenance Policy for Imperfect Process Manufacturing Cell
}

\author{
K. Dhouib, A. Gharbi, M.N. Ben Aziza \\ Automated Production Engineering Department, École de Technologie Supérieure, \\ Production System Design and Control Laboratory, \\ University of Québec, 1100 Notre-Dame Street West, Montréal, Québec, Canada H3C 1 K3
}

\begin{abstract}
Production, maintenance, and quality are often modeled as separate problems, despite the strong link that exists between these primary components of any manufacturing system. This paper deals with an integrated approach for the joint optimization of production-inventory control and preventive maintenance policy for a manufacturing cell comprising an imperfect process where the 'in-control' period have a general deterioration distribution. The production-inventory control policy based on the hedging point policy consists of building and maintaining a security stock of finished products in order to respond to demand and to avoid shortages during restoration actions. Restoration actions are planned when the system switches to the 'out-of-control' state and starts producing non-conforming items. The manufacturing cell is also subject to an age-based preventive maintenance policy in order to reduce the shift rate to the 'out-of-control' state. The main objective of this paper is to determine the joint optimal policy that minimizes the overall cost, which is comprised of setup, maintenance, inventory holding and shortage costs, as well as the cost incurred by producing non-conforming items. A mathematical model is proposed, and the expression of the overall incurred cost is derived and used as a basis for the optimal determination of the joint production-inventory control and preventive maintenance policy. These issues are illustrated using numerical examples. It is found that performing preventive maintenance will yield reductions in the overall incurred cost. Sensitivity analyses are also carried out in order to illustrate the robustness of the proposed methodology.
\end{abstract}

Keywords: Production-inventory control, age-based preventive maintenance, product quality deterioration, joint optimal policy, manufacturing cell.

\section{Introduction}

Manufacturing system performance is affected mainly by random phenomena such as machine breakdowns and product quality deterioration. In order to respond to demand requests, manufacturing equipment must be maintained in top operating condition through adequate maintenance programs. Despite the fact that production, maintenance, and quality seem to be so closely related to one another, most research does not integrate them into a single model in order 
to analyze their underlying interactions and their impact on the global performance of manufacturing systems. Indeed, manufacturing systems start in an 'in-control' state, producing conforming items of acceptable quality. However, and after a random span, they shift to the 'outof-control' state and start producing non-conforming items (Ben-Daya (2002), Chelbi et al. (2008), Radhoui et al. (2009)). In practice, preventive maintenance should reduce the frequency of transition to the out-of-control state and the production rate of non-conforming items. These aspects will improve the manufacturing system throughput, its capability to respond to the demand by avoiding shortages, and will reduce the overall incured cost.

Due to complexity considerations, various event-oriented models have been developed to face the uncertainties implicit in the sub-classes of manufacturing systems considered. The different contributions associated with integrated models covered in the literature can be classified as follows: (1) joint production and maintenance problems, (2) joint production and quality problems, and (3) joint production, maintenance, and quality problems.

During the last decades, several production control and maintenance policies have been proposed in order to improve manufacturing system performance. Kimemia and Gershwin (1983), and Akella et al. (1984) have considered the production control problem for systems prone to failures. Akella and Kumar (1986) have introduced the Hedging Point Policy (HPP), which entails that the buffer stock be built up with an excess production capacity and then maintained at its maximum level in order to palliate for interruptions due to breakdowns. Akella and Kumar (1986), and Feng and Xiao (2002) have shown that the HPP policy is optimal for systems prone to failures described by homogeneous Markov processes (i.e., time-invariant up and down transition rates), and that are thus only subject to corrective maintenance.

To attenuate the impact of failures on the overall performance of manufacturing systems, Barlow and Hunter (1960) introduced the age replacement policy (ARP) concept, which consists of replacing a unit at failure or whenever it reaches a constant threshold age $T$. They also bring in the notion of the block replacement policy (BRP), under which units are replaced at failure or at fixed intervals $k T(k=1,2 \ldots)$ independent of the unit age. Detailed comparisons of the ARP and BRP are proposed by Barlow and Proschan (1965), who find mainly that the ARP is economically superior to the BRP.

A significant portion of the literature is devoted to the cost minimization through combined preventive maintenance and production/inventory control policies. These mathematical models combine BRP or ARP with production/inventory control policies to respond to demand during maintenance activities (Ki Ling and Hausman (1997), Salameh and Ghattas (2001), Tadashi et al. (2001), Chelbi and Ait-Kadi (2004), Kenné et al. (2007), Gharbi et al. (2007), Chelbi et al. (2008), Rezg et al. (2008), Berthaut et al. (2011)).

In considering manufacturing processes, many authors looked at defective items in order to tackle the economic order/manufacturing quantity problem (i.e., EOQ/EMQ) (Porteus (1986), Lee and Rosenblatt (1987), Hariga and Ben-Daya (1998), Goyal and Cardenas-Barron (2002), Ben-Daya et al. (2006), We et al. (2007), Ben-Daya and Noman (2008)).

More recently, a few researchers have proposed integrated models linking the preventive maintenance, product quality, and production components. Most such proposed models consider 
manufacturing systems composed of a single imperfect machine manufacturing a single product to respond to a constant and continuous demand. Ben-Daya (1999, 2002), and Ben-Daya and Rahim (2000) propose original models for the joint optimization of the economic manufacturing quantity, the economic design of $\bar{x}$ control charts, and the optimal maintenance level for a single product, deteriorating mono processor systems. The proposed models do not consider the impact of shortage situations on the optimal policy. Chelbi et al. (2008) propose an integrated production-maintenance strategy for a single product, single machine system producing conforming and non-conforming items. The proposed model aims to simultaneously find the economic manufacturing quantity and the optimal age $T$ at which preventive maintenance must be performed. Unlike models based on the production control concept (Gharbi et al. (2007), Chelbi et al. (2008)), these models consider that the manufacturing process will produce a specific quantity, the EMQ, and then shut down until the inventory is complete depleted. Radhoui et al. (2009) propose a joint quality control, preventive maintenance, and production control policy for a single product, single machine system producing conforming and nonconforming items. The proposed policy does not consider a continuous inspection of manufactured products, but requires that the quality of each manufactured lot be controlled with a specific size, and according to the percentage of non-conforming items noted, a decision is made to either continue or to stop production in order to perform a preventive or a corrective action. A simulation-based approach is considered in order to simultaneously determine the optimal policy parameters which minimize the expected total cost per time unit.

This paper investigates the contribution of integrating a production-inventory control policy and a preventive maintenance policy in order to attenuate the impact of non-conforming items on the overall performance of a manufacturing cell composed of an automatic machine. The manufacturing cell is dedicated to producing a single product type, and is subject to quality deterioration. The production-inventory control policy is based on the HPP policy (Akella and Kumar (1986)), under which the manufacturing cell operates, initially, at a maximum production rate in order to satisfy demand and to build up a buffer stock. Once the buffer stock is built, the production rate is reduced in order to satisfy the demand rate. This buffer stock is put in place to palliate shortage situations during restoration actions, which for their part are planned when the system switches to the 'out-of-control' state and starts producing non-conforming items. An agebased preventive maintenance policy (APM) is also considered in order to reduce the probability of shifting to the 'out-of-control' state. After a random period of time spent producing conforming items, the manufacturing cell can shift to the 'out-of-control' state and start producing a percentage of non-conforming items. A restoration action of random duration then takes place following a logistic period used to prepare all required resources. The manufacturing cell machine is then restored to the 'as-good-as-new' 'in-control' state, and once again starts producing conforming items.

A mathematical model considering all possible scenarios that can occur depending on the instant at which the manufacturing cell shifts to the 'out-of-control' state, is proposed, and allows a more realistic consideration of the real behavior of manufacturing cells. The model determines the joint optimal production-inventory control and age-based preventive maintenance policy (i.e., the HPP/APM policy) which minimizes the total average cost per time unit over an infinite horizon. The total cost includes the setup, preventive maintenance, restoration, inventory holding and the shortage costs, as well as the costs incurred by producing non-conforming items. A 
solution procedure is also proposed to assess the optimal inventory size and the age at which preventive maintenance actions must be performed.

The remainder of the paper is organized as follows. The system description and its dynamic and stochastic behaviors are discussed in Section 2. Section two also presents basic notations and assumptions. The joint production-inventory control, preventive maintenance, and product quality model is developed in Section 3. Section 4 presents a numerical procedure for solving the proposed model, some numerical results to illustrate important issues related to the model, and a sensitivity analysis to demonstrate its robustness. Finally, Section 5 contains a summary of the paper and some concluding remarks.

\section{Manufacturing system description}

\subsection{System description}

Consider a manufacturing cell composed of an automatic machine dedicated to producing a single product type to satisfy a constant and continuous demand at rate $d$. The automatic machine can operate at maximum capacity at rate $U_{\max }$, where $U_{\max }>d$. The manufacturing cell is subject to random perturbations caused by product quality deterioration. Initially, the manufacturing cell starts in an 'in-control' state, producing conforming items of acceptable quality. After a random operating period $(\tau)$, the manufacturing process may shift from the 'in-control' state to the 'outof-control' state and starts producing a percentage $(\alpha)$ of non-conforming items. In spite of outof-order situations where the production process is aborted, during out-of-control situations, the manufacturing cell continues to producing conforming and no-conforming items. The automatic manufacturing cell machine allows the instantaneous detection of the 'out-of-control' state. The 'in-control' state period is a random variable with general probability distribution having an increasing hazard rate. $f(\tau)$ and $F(\tau)$ are respectively the density and distribution functions associated with the random variable $\tau$.

In order to reduce the shift rate to the 'out-of-control' state, preventive maintenance actions requiring negligible time periods are planned during the 'in-control' state period. The preventive maintenance policy is based on an ARP policy with a threshold age $T$.

Upon transition to the 'out-of-control' state, a restoration action is started after a constant delay, denoted Logistic Delay Period $(L D P)$. During $L D P$, the manufacturing cell continues to producing conforming and non-conforming items. The $L D P$ is required in preparing all resources (human and material) necessary for restoration actions. During restoration actions, the production process is aborted. The restoration action delay $\left(t_{r}\right)$ is a random variable having a general probability distribution with mean value MTTR (i.e., Mean Time To Restore). $h\left(t_{r}\right)$ and $H\left(t_{r}\right)$ are respectively the density and distribution functions associated with the random variable $t_{r}$.

The manufacturing cell production process is controlled over time by a production-inventory control policy based on the HPP policy in order to respond to demand and to avoid shortages during restoration actions. The HPP policy entails that the manufacturing cell be operated at maximum capacity $\left(U_{\max }\right)$ until a security stock of finished products with capacity $Z$ is built, after 
which, it will be maintained during the production phase until the beginning of the restoration action. After a preventive maintenance or a restoration action, the manufacturing facility transits to the 'as-good-as-new' 'in-control' state and starts producing conforming items. Although additional capacity generally implies additional cost, in this paper we consider that the operating cost of the manufacturing cell is constant since capacity decision is rather strategic than operational decision. In effect, most manufacturing systems were designed with additional capacity in order to palliate several perturbations such as demand increasing and variability, supplier's weaknesses and failures, production variations, equipment breakdowns, quality deterioration, etc.

Once restorations are achieved, the production process is resumed only when the on-hand inventory is exhausted (no-resumption policy is considered (Groenevelt et al. (1992))). In effect, many authors show that it is not optimal to build up the security stock immediately after restoration action is completed, and that the inventory construction can begin after a specific period from the production start up (Salamah and Ghattas (2001), Gharbi Kenné et al. (2007)). A setup action with a cost $C_{S U}$ and with a negligible delay is then carried out before the production process is restarted. During a restoration action, an inventory shortage may occur due to longer restoration delays. In such cases, quantities required during a shortage period are not delivered after the manufacturing cell restoration, and are considered as lost demand. The objective is to find the joint production flow rate control and the preventive maintenance strategy, that minimizes the expected total quality, preventive maintenance, restoration, setup, inventory holding and shortage costs per unit of time, as depicted in figure 1.

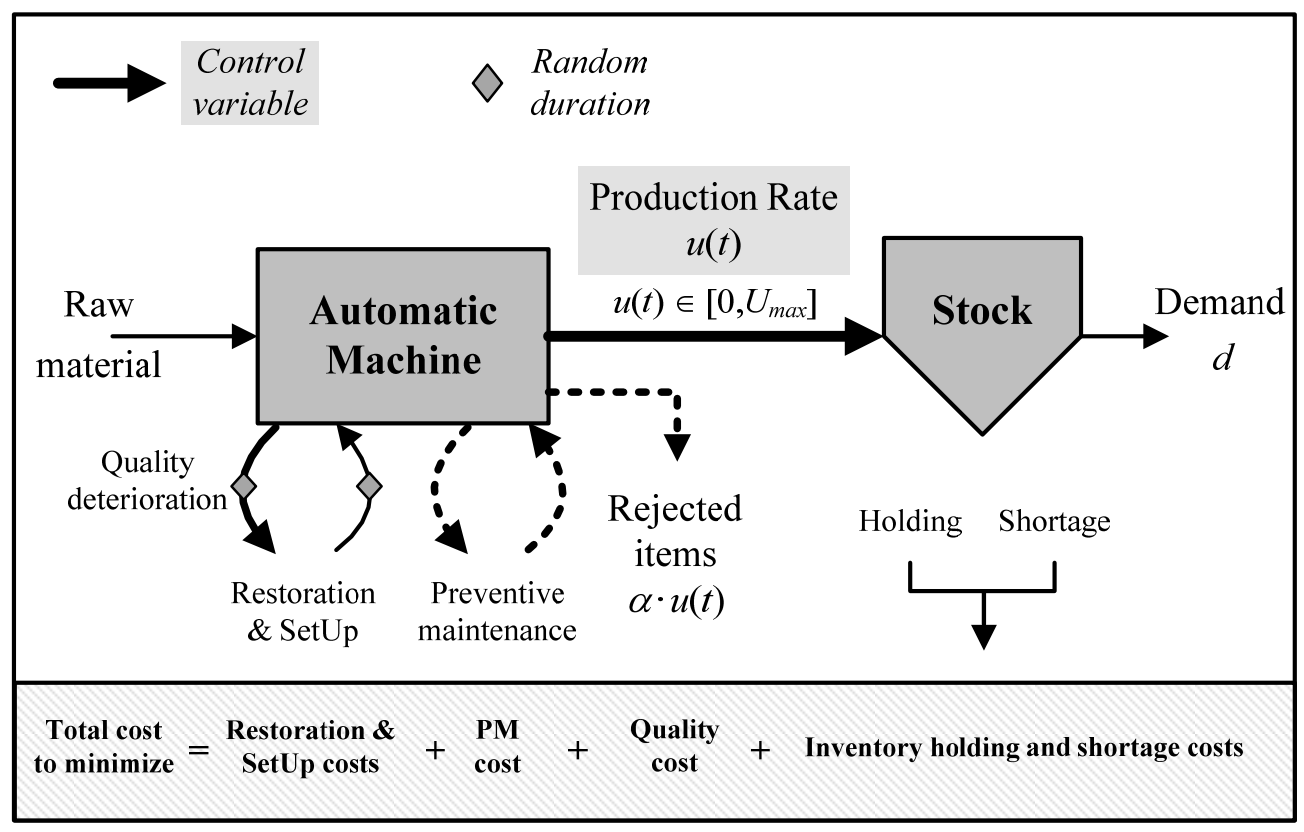

Fig. 1 Manufacturing system dynamics

\subsection{Stochastic and dynamic behaviour of the manufacturing cell}


The manufacturing cell state evolves in a cyclic renewal manner since the time interval between two successive production start points constitutes a complete cycle including the production and the restoration phases. In fact, a renewal cycle starts with a renewed manufacturing cell having a zero inventory level and ends with a machine that is restored to the 'as-good-as-new' 'in-control' state with a zero inventory level. During the production phase, and depending on the random instant at which the automatic machine shifts to the 'out-of-control' state, the manufacturing cell can be in one of the three following scenarios, denoted Scenarios 1, 2, and 3.

\subsubsection{Scenario 1: Preparation for restoration ends before reaching security stock capacity}

This scenario occurs when the manufacturing cell shifts to the 'out-of-control' state and the preparation for the restoration action ends before the maximum inventory level $\mathrm{Z}$ is reached (Fig. 2). In order to reduce the shortage probability during the restoration phase, the manufacturing cell continues production during the 'out-of-control' state until it builds the security stock. At that point, the production process is aborted, and the restoration activity starts immediately.

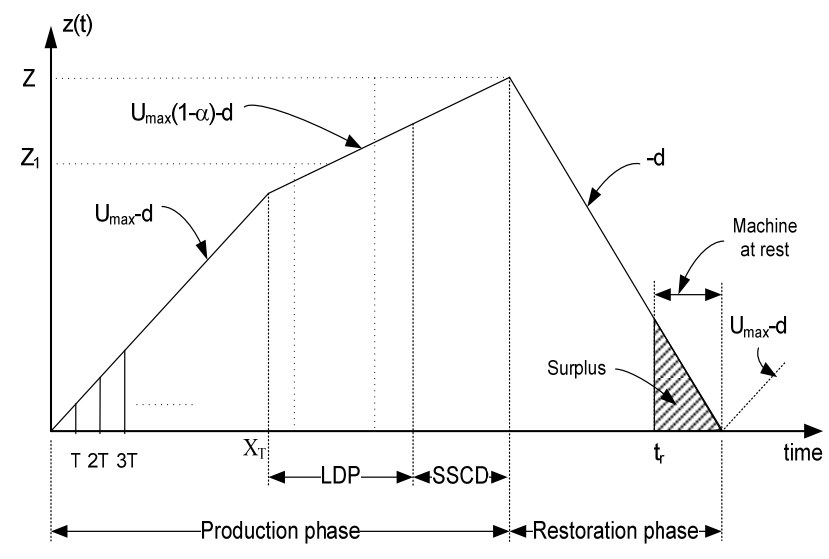

(a) Surplus Situation

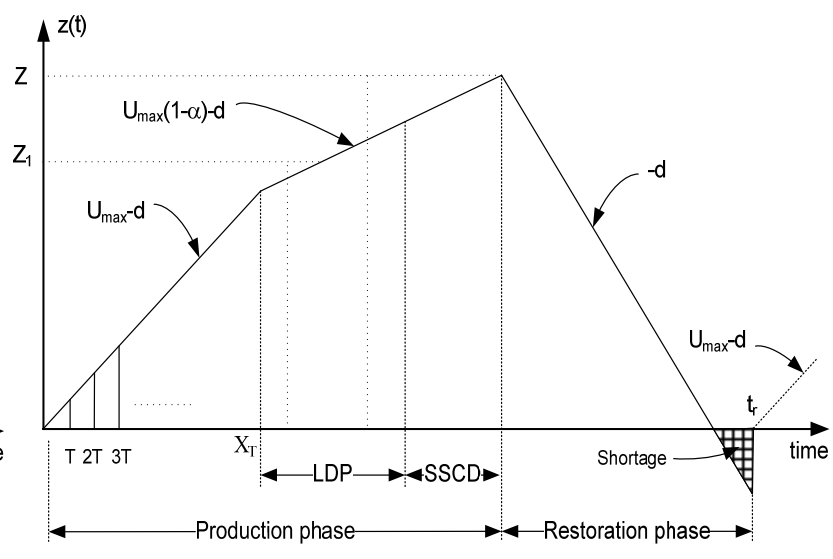

(b) Shortage situation

Figure 2 Inventory evolution according to Scenario 1

The occurrence of Scenario 1 is constrained by condition (1), where $Z_{1}$ is the critical inventory level from which the preparation for the restoration action ends after the building of the security stock (Eq. 2); $X_{T}$ is the time to shift to the 'out-of-control' state under an APM policy with threshold age $T$ and SSCD (i.e., Security Stock Completion Delay) is the delay required to reach the maximum inventory level $(Z)$ after achieving the preparation activity for restoration.

$$
\begin{aligned}
& X_{T}<\frac{Z_{1}}{U_{\text {max }}-d} \\
& Z_{1}=Z-\left[\left(U_{\text {max }}(1-\alpha)-d\right) L D P\right]
\end{aligned}
$$


During the production phase, the manufacturing cell produces at its maximum production rate $\left(U_{\max }\right)$. However, stock replenishment is performed according to two different rates:

- $\left(U_{\max }-d\right)$ for as long as the manufacturing cell is in the 'in-control' state.

- $\left(U_{\max }(1-\alpha)-d\right)$ once the manufacturing cell shifts to the 'out-of-control' state, and providing the security stock is not yet built.

\subsubsection{Scenario 2: Transition to the 'out-of-control' state occurs before, and preparation for restoration ends after, reaching security stock capacity}

According to this scenario, the transition to the 'out-of-control' state occurs after the critical inventory level $Z_{1}$ is reached, and before building the security stock (Fig. 3).

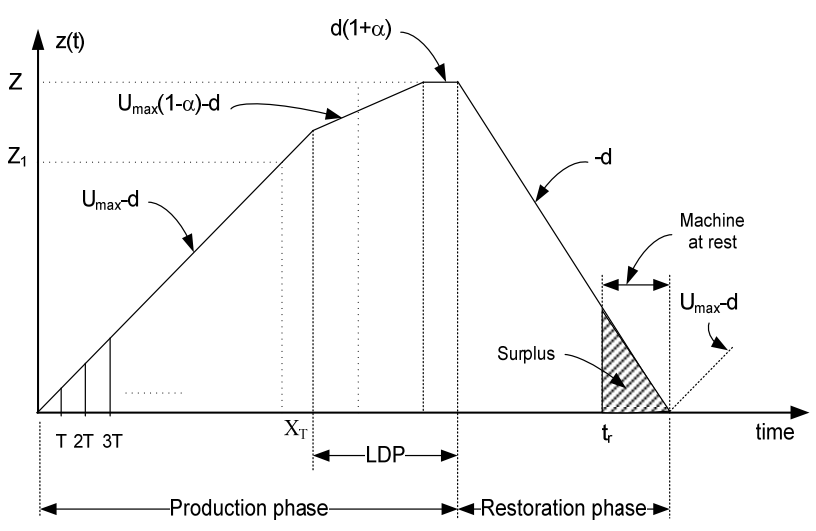

(a) Surplus situation

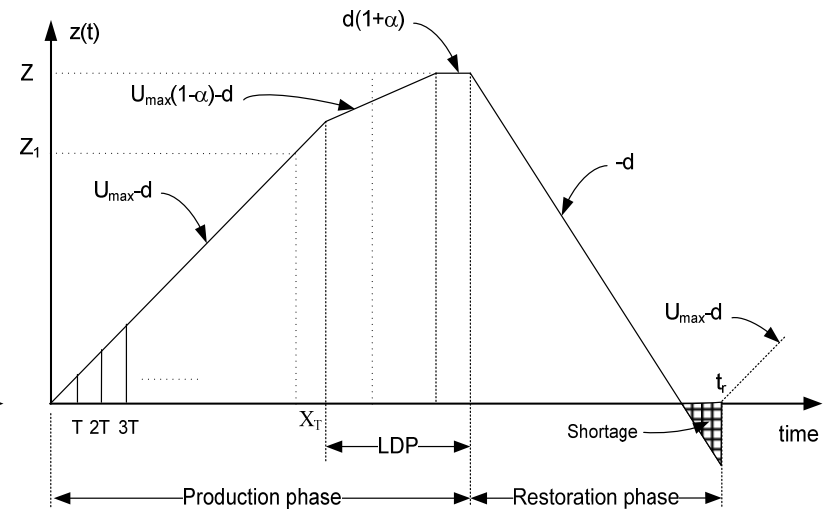

(b) Shortage situation

Figure 3 Inventory evolution according to Scenario 2

The occurrence of Scenario 2 is constrained by the following condition:

$$
\frac{Z_{1}}{U_{\max }-d}<X_{T}<\frac{Z}{U_{\max }-d}
$$

With Scenario 2, and during the production phase, the manufacturing cell produces according to two different rates:

- Maximum rate $U_{\max }$ before the maximum inventory level $Z$ is reached.

- Adjusted rate $d(1+\alpha)$ once the maximum inventory level $Z$ is reached.

The stock replenishment is also performed according to two different rates:

- $\left(U_{\max }-d\right)$ for as long as the manufacturing cell is in the 'in-control' state.

- $\left(U_{\max }(1-\alpha)-d\right)$ once the manufacturing cell shifts to the 'out-of-control' state, and provided that the security stock is not yet built. 


\subsubsection{Scenario 3: Transition to the 'out-of-control' state occurs after reaching stock level Z}

The occurrence of Scenario 3 is constrained by the following condition:

$$
X_{T}>\frac{Z}{U_{\text {max }}-d}
$$

Accordingly, Scenario 3 happens if the transition to the 'out-of-control' state occurs after the security stock is built (Fig. 4).

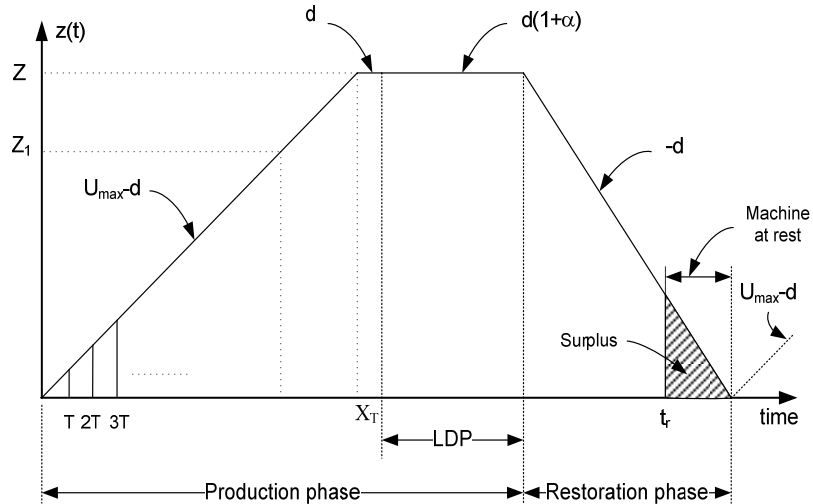

(a) Surplus situation

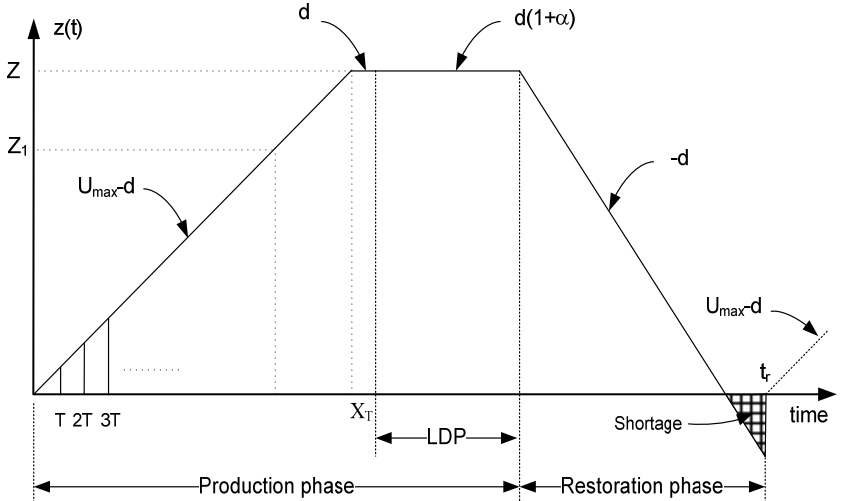

(b) Shortage situation

Figure 4 Inventory evolution according to Scenario 3

During the production phase, the manufacturing cell produces according to three different rates:

- Maximum rate $U_{\max }$ before the maximum inventory level $Z$ is reached.

- Demand rate $d$ after the maximum inventory level $Z$ is reached, and for as long as the manufacturing cell remains in the 'in-control' state.

- Adjusted rate $d(1+\alpha)$ during the preparation action for restoration $(L D P)$.

On the other hand, the stock replenishment is performed according to the rate $\left(U_{\max }-d\right)$.

Figures 2, 3, and 4 also show that whatever the scenario being considered, the inventory level behavior during the restoration phase remains unchanged. In fact, the restoration phase begins with a full inventory and ends either with a surplus (Figs. 2(a), 3(a), 4(a)) or a shortage situation (Figs. 2(b), 3(b), 4(b)), depending on the length of the random restoration period $\left(t_{r}\right)$.

\section{Overall cost mathematical model}

In this section, we formulate the mathematical model of the overall cost incurred by the joint HPP/APM policy of the imperfect manufacturing cell considered. The overall cost is composed of the incurred costs during the production phase and those incurred during the restoration phase, when the manufacturing cell is shut down. 
The joint optimal HPP/APM policy is determined by the optimal values of the security stock capacity and the threshold age at which preventive maintenance activities are carried out $\left(Z^{*}, T^{*}\right)$, which minimize the overall expected cost per time unit through an infinite horizon $\left(C_{t}\right)$. Therefore, the related optimal control policy is given by equation (5) where $u(t)$ is the controlled production rate of the manufacturing system and $z(t)$ is the inventory level at time $\mathrm{t}$; if $z(t)$ is positive, it represents inventory surplus, while a negative value represents a shortage.

$$
u(t)= \begin{cases}U_{\max } & \text { if } z(t)<Z^{*} \\ d & \text { if } z(t)=Z^{*} \text { and the system is in the 'in-control' state } \\ d(1+\alpha) & \text { if } z(t)=Z^{*} \text { and the system is in the 'out-of-control' state } \\ 0 & \text { if } z(t)>Z^{*}\end{cases}
$$

According to the renewal reward theorem, the overall expected cost $\left(C_{t}\right)$ is equal to the weighted expected cost per time unit incurred during the production and restoration phases by the occurrence of Scenarios 1, 2, and 3, during inventory surplus or shortage situations (Eq. 6).

$$
C_{t}=\sum_{i=1}^{3}\left(\frac{\left(C F_{i}+C R_{H}\right)}{L C_{i H}} \operatorname{Pr}_{H}+\frac{\left(C F_{i}+C R_{S}\right)}{L C_{i S}} \operatorname{Pr}_{S}\right) \operatorname{Pr}_{i}
$$

where $C F_{i}(i=1,2,3)$ denotes the cost incurred during the production phase upon occurrence of Scenario $i$; $\operatorname{Pr}_{i}$ denotes the probability of occurrence of Scenario $i ; L C_{i H}$ and $L C_{i S}$ respectively denote the expected length of a production/restoration cycle upon occurrence of Scenario $i$ and during inventory surplus or shortage situations; $C R_{H}$ and $C R_{S}$ respectively denote the costs incurred during the restoration phase upon occurrence of surplus and shortage situations, and $\operatorname{Pr}_{H}$ and $\operatorname{Pr}_{S}$ respectively denote the probabilities of occurrence of surplus and shortage situations.

The next paragraphs formulate the explicit analytical expressions of the various components of the overall expected cost incurred by the joint HPP/APM management policy of the manufacturing cell (Eq. 6). The probabilities $\operatorname{Pr}_{i}, \operatorname{Pr}_{H}, \operatorname{Pr}_{S}$, and the expected lengths of a production/restoration cycle $\left(L C_{i H}, L C_{i S}\right)$ associated with various scenarios will first be determined. Next, the detailed analytical expressions of the incurred costs during production and restoration phases will be developed.

\subsection{Probabilities of occurrence of various scenarios}

\subsubsection{Probability of occurrence of Scenario 1}

Let $N_{1}$ be the maximum number of preventive maintenance actions at age $T$ that the manufacturing cell can undertake before the critical inventory level $Z_{1}$ is reached. $N_{1}$ is given by:

$$
N_{1}=\frac{Z_{1}}{U_{\max }-d} \operatorname{div} T
$$


where $a \operatorname{div} b$ denotes the result of the integer division of $a$ by $b$.

The probability of being in Scenario $1\left(\operatorname{Pr}_{1}\right)$ is equal to the probability of the manufacturing cell shifting to the 'out-of-control' state before the execution of the first, the second, ..., the $N_{1}$ th preventive maintenance action, or after the execution of the $N_{1}$ th preventive maintenance action, and before the critical inventory level $Z_{1}$ is reached. The probability $\operatorname{Pr}_{1}$ can be expressed by:

$$
\operatorname{Pr}_{1}=\sum_{n=0}^{\left(N_{1}-1\right)} R(T)^{n} F(T)+R(T)^{N_{1}} F\left(\frac{Z_{1}}{U_{\max }-d} \bmod T\right)
$$

where $a \bmod b$ denotes the rest of the integer division of $a$ by $b$, and $R(\tau)$ is the reliability function of the random variable $\tau(R(\tau)=1-F(\tau))$.

\subsubsection{Probability of occurrence of Scenario 2}

Let $N$ be the maximum number of preventive maintenance actions at age $T$ that the manufacturing cell can undertake before the maximum inventory level $Z$ is reached. $N$ is given by:

$$
N=\frac{Z}{U_{\max }-d} \operatorname{div} T
$$

The occurrence probability of Scenario $2\left(\mathrm{Pr}_{2}\right)$ is equal to the probability of the manufacturing cell shifting to the 'out-of-control' state while the inventory level is comprised between $Z_{1}$ and $Z$. The probability $\operatorname{Pr}_{2}$ can be determined by:

$$
\operatorname{Pr}_{2}=R(T)^{N_{1}}\left(F(T)-F\left(\frac{Z_{1}}{U_{\text {max }}-d} \bmod T\right)\right)+F(T) \sum_{n=N_{1}+1}^{N-1} R(T)^{n}+R(T)^{N} F\left(\frac{Z}{U_{\text {max }}-d} \bmod T\right)
$$

\subsubsection{Probability of occurrence of Scenario 3}

The occurrence probability of Scenario $3\left(\operatorname{Pr}_{3}\right)$ is equal to the probability of the manufacturing cell shifting to the 'out-of-control' state while the security stock is already built. The probability $\mathrm{Pr}_{3}$ can be deduced by:

$$
\mathrm{Pr}_{3}=1-\left(\mathrm{Pr}_{1}+\mathrm{Pr}_{2}\right)
$$

\subsubsection{Probability of occurrence of an inventory surplus situation}

The occurrence probability of an inventory surplus situation $\left(\operatorname{Pr}_{H}\right)$ after the completion of a restoration action is independent of the scenario that can occur during the production phase. The probability $\operatorname{Pr}_{H}$ is given by: 


$$
\operatorname{Pr}_{H}=\int_{0}^{Z / d} h\left(t_{r}\right) d t_{r}=H(Z / d)
$$

where $\mathrm{Z} / \mathrm{d}$ is the time during which the entire safety stock will be consumed by the demand.

\subsubsection{Probability of occurrence of a shortage situation}

The occurrence probability of a shortage situation $\left(\operatorname{Pr}_{S}\right)$ after the completion of a restoration action is also independent of the scenario that can occur during the production phase. The probability $\operatorname{Pr}_{S}$ can be deduced by:

$$
\operatorname{Pr}_{S}=1-\operatorname{Pr}_{H}
$$

\subsection{Expected length of a production/restoration cycle}

The expected length of a production/restoration cycle depends on the scenario that can occur during the production phase and upon occurrence of a surplus or a shortage situation further to a restoration action. The expected length of a production/restoration cycle includes the mean life time before transiting to the 'out-of-control' state, the logistic delay period required to prepare the resources for the restoration action, and the mean restoration time in a shortage situation or the time required to consume the entire security stock in an inventory surplus situation.

\subsubsection{Expected cycle length upon occurrence of Scenario 1}

In case of occurrence of Scenario 1, and if the restoration action ends with a surplus inventory (Fig. 2(a)), the expected length of the production/restoration cycle $\left(L C_{1 H}\right)$ is given by:

$$
L C_{1 H}=E_{1}\left(X_{T}\right)+L D P+S S C D+Z / d
$$

where $E_{1}\left(X_{T}\right)$ is the mean life time of the manufacturing cell in the 'in-control' state upon occurrence of Scenario 1.

The manufacturing cell life time upon occurrence of Scenario 1 is a continuous time random variable, depending on the threshold age $T$, and defined on interval $\left[0, Z_{1} /\left(U_{\max }-d\right)\right]$. Consequently, $E_{1}\left(X_{T}\right)$ can be expressed by:

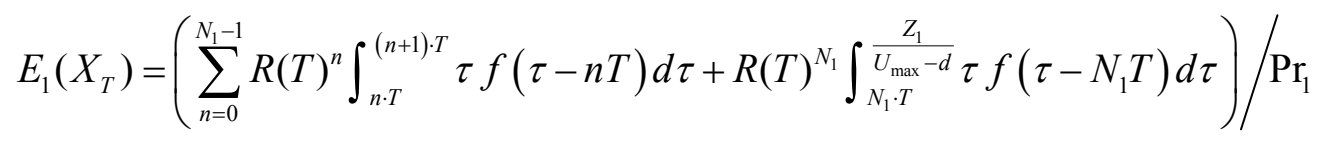

The required expected delay to reach the maximum inventory level after the completion of a preparation action for restoration $(S S C D)$ is given by equation (16) where the logistic delay period $(L D P)$ is assumed to be constant. Indeed, the resources required for restoration action are considered available and internal to the company. 


$$
S S C D=\frac{Z-\left[\left(U_{\max }(1-\alpha)-d\right) L D P+\left(U_{\max }-d\right) E_{1}\left(X_{T}\right)\right]}{U_{\max }(1-\alpha)-d}
$$

If the security stock cannot respond to the demand during the restoration period, a shortage situation is observed (Fig. 2(b)). Therefore, the expected length of the production/restoration cycle is given by:

$$
L C_{1 S}=E_{1}\left(X_{T}\right)+L D P+S S C D+E_{S}\left(t_{r}\right)
$$

where $E_{S}\left(t_{r}\right)$ is the expected time to restore the manufacturing cell in a shortage situation:

$$
E_{S}\left(t_{r}\right)=\int_{Z / d}^{\infty} t_{r} h\left(t_{r}\right) d t_{r} / \operatorname{Pr}_{S}
$$

\subsubsection{Expected cycle length upon occurrence of Scenario 2}

In case of occurrence of Scenario 2, and if the restoration action ends with a surplus inventory (Fig. 3(a)), the expected length of the production/restoration cycle $\left(L C_{2 H}\right)$ is given by:

$$
L C_{2 H}=E_{2}\left(X_{T}\right)+L D P+Z / d
$$

where $E_{2}\left(X_{T}\right)$ is the mean life time of the manufacturing cell 'in-control' state upon occurrence of Scenario 2.

The manufacturing cell life time upon occurrence of Scenario 2 is a continuous time random variable, depending on the threshold age $T$, and defined on interval $\left[Z_{1} /\left(U_{\max }-d\right), Z /\left(U_{\max }-d\right)\right]$. Consequently, $E_{2}\left(X_{T}\right)$ can be expressed by:

$$
E_{2}\left(X_{T}\right)=\left(\begin{array}{l}
R(T)^{N_{1}} \int_{\frac{Z_{1}}{U_{\max }-d}}^{\left(N_{1}+1\right) T} \tau f\left(\tau-N_{1} T\right) d \tau+\sum_{n=N_{1}+1}^{N-1} R(T)^{n} \int_{n T}^{(n+1) T} \tau f(\tau-n T) d \tau \\
+R(T)^{N} \int_{N T}^{\frac{Z}{U_{\max }-d}} \tau f(\tau-N T) d \tau
\end{array}\right) / \operatorname{Pr}_{2}
$$

If a shortage situation is observed (Fig. 3(b)), the expected length of the production/restoration cycle is given by:

$$
L C_{2 S}=E_{2}\left(X_{T}\right)+L D P+E_{S}\left(t_{r}\right)
$$

\subsubsection{Expected cycle length upon occurrence of Scenario 3}

If the restoration action ends with a surplus inventory after the occurrence of Scenario 3 (Fig. 4(a)), the expected length of the production/restoration cycle $\left(L C_{3 H}\right)$ is given by: 


$$
L C_{3 H}=E_{3}\left(X_{T}\right)+L D P+Z / d
$$

where $E_{3}\left(X_{T}\right)$ is the mean life time of the manufacturing cell 'in-control' state upon occurrence of Scenario 3 .

The manufacturing cell life time upon occurrence of Scenario 3 is a continuous time random variable, depending on the threshold age $T$, and defined on interval $\left[Z /\left(U_{\max }-d\right), \infty\right]$. Consequently, $E_{3}\left(X_{T}\right)$ can be expressed by:

$$
E_{3}\left(X_{T}\right)=\left(R(T)^{N} \int_{\frac{z}{U_{\max }-d}}^{(N+1) T} \tau f(\tau-N T) d \tau+\sum_{n=N+1}^{\infty} R(T)^{n} \int_{n T}^{(n+1) T} \tau f(\tau-n T) d \tau\right) / \operatorname{Pr}_{3}
$$

Upon occurrence of a shortage situation (Fig. 3(b)), the expected length of the production/restoration cycle, denoted $L C_{3 S}$, is given by:

$$
L C_{3 S}=E_{3}\left(X_{T}\right)+L D P+E_{S}\left(t_{r}\right)
$$

\subsection{Expected cost incurred during production phase}

The costs incurred during the production phase upon occurrence of scenario $i(i=1,2,3)$ consists of the setup, inventory holding, preventive maintenance, and non-conforming item costs (Eq. 25).

$$
C F_{i}=C_{S U}+C P M_{i}+C I_{i}+C N C_{i}
$$

where $C P M_{i}, C I_{i}$, and $C N C_{i}$ are respectively the expected costs for preventive maintenance, inventory holding, and non-conforming items produced upon occurrence of Scenario $i$.

\subsubsection{Expected preventive maintenance cost}

The expected cost for preventive maintenance $\left(C P M_{i}\right)$ is equal to the product of the unit cost of a preventive maintenance action $\left(C_{P M}\right)$ by the expected number of preventive actions carried out upon occurrence of Scenario $i\left(E_{i}(N P M)\right)$ (Eq. 26).

$$
C P M_{i}=C_{P M} E_{i}(N P M)
$$

Considering Scenario 1, the number of preventive maintenance actions $(N P M)$ is finite since the transition to the 'out-of-control' state can only occur before the inventory level threshold $Z_{1}$ is reached. Consequently, the variable $N P M$ is a discrete integer random variable taking its values in the interval $\left[0, N_{1}\right]$ (Fig. 5-a). The expected number of preventive actions carried out upon occurrence of Scenario 1 can be expressed by: 


$$
E_{1}(N P M)=\left(\sum_{n=0}^{N_{1}-1} n R(T)^{n} F(T)+N_{1} R(T)^{N_{1}} F\left(\frac{Z_{1}}{U_{\max }-d} \bmod T\right)\right) / \operatorname{Pr}_{1}
$$

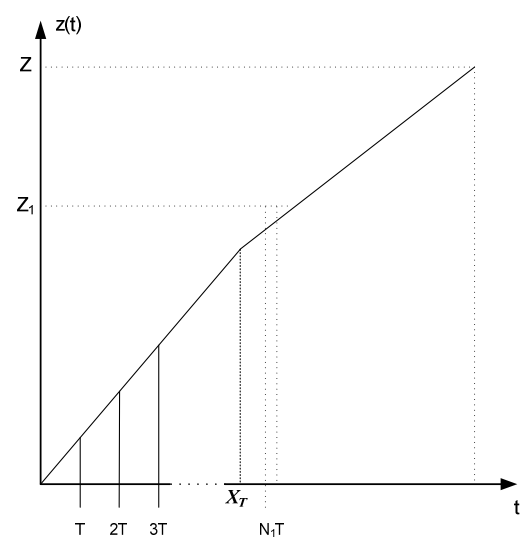

(a) Scenario 1

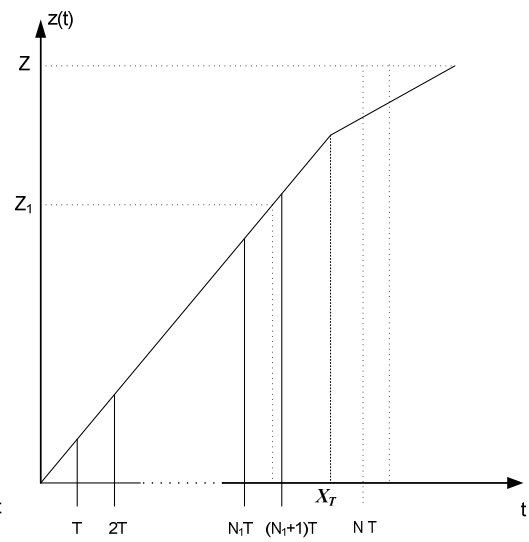

(b) Scenario 2

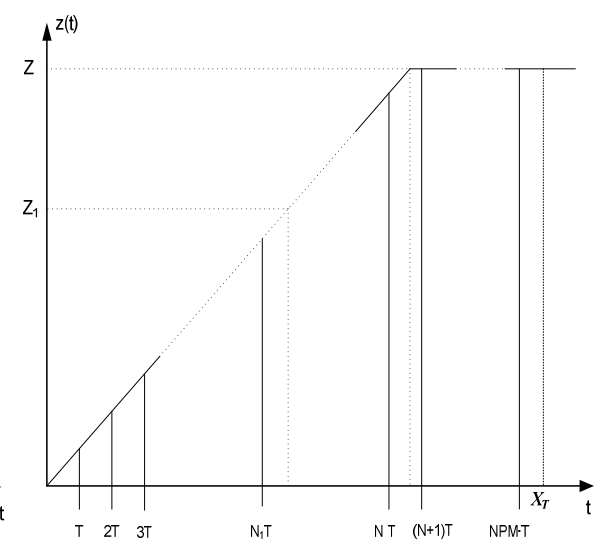

(c) Scenario 3

Figure 5 Preventive maintenance actions performed during production phase

Upon occurrence of Scenario 2, the number of preventive maintenance actions is also finite since the transition to the 'out-of-control' state can only occur before the maximum inventory level $Z$ is reached. Consequently, the variable $N P M$ is a discrete integer random variable taking its values in the interval $\left[N_{1}, N\right]$ (Fig. 5-b). Thus, the expected number of preventive maintenance actions performed during the occurrence of Scenario 2 is given by:

$$
E_{2}(N P M)=\left(\begin{array}{l}
N_{1} R(T)^{N_{1}}\left(F(T)-F\left(\frac{Z_{1}}{U_{\max }-d} \bmod T\right)\right)+\sum_{n=N_{1}+1}^{N-1} n R(T)^{n} F(T) \\
+N R(T)^{N} F\left(\frac{Z}{U_{\max }-d} \bmod T\right)
\end{array}\right) / \operatorname{Pr}_{2}
$$

Contrary to Scenarios 1 and 2 where the number of preventive actions is finite, the number of preventive maintenance actions upon occurrence of Scenario 3 can tend towards infinity. In fact, the variable $N P M$ is a discrete integer random variable taking its values in the interval $[N, \infty]$ (Fig. 5-c). Accordingly, the expected number of preventive actions performed upon occurrence of Scenario 3 can be evaluated by:

$$
E_{3}(N P M)=\left(N R(T)^{N}\left(F(T)-F\left(\frac{Z}{U_{\max }-d} \bmod T\right)\right)+\sum_{n=N+1}^{\infty} n R(T)^{n} F(T)\right) / \operatorname{Pr}_{3}
$$

\subsubsection{Expected cost for inventory holding}


The expected cost for inventory holding $\left(C I_{i}\right)$ can be evaluated by multiplying one item holding cost per unit time $\left(C_{I}\right)$ by the average quantity held in security stock during the production phase upon occurrence of Scenario $i(\overline{I H})$ (Eq. 30).

$$
C I_{i}=C_{I} \overline{I H_{i}}
$$

The average quantity held in stock can be evaluated by considering the surface under the curve of evolution of the inventory during the production phase (Fig. 6). Consequently, $\overline{I H_{1}}, \overline{I H_{2}}$, and $\overline{I_{3}}$ are evaluated respectively by the equations (31), (32), and (33).

$$
\begin{aligned}
& \overline{I H_{1}}=\left(U_{\max }-d\right) E_{1}\left(X_{T}\right)\left(\frac{E_{1}\left(X_{T}\right)}{2}+(L D P+S S C D)\right)+\left(U_{\max }(1-\alpha)-d\right) \frac{(L D P+S S C D)^{2}}{2} \\
& \overline{I H_{2}}=\frac{\left(U_{\max }-d\right) E_{2}\left(X_{T}\right)^{2}}{2}+\frac{Z^{2}-\left(U_{\text {max }}-d\right)^{2}\left(E_{2}\left(X_{T}\right)\right)^{2}}{2\left(U_{\text {max }}(1-\alpha)-d\right)}+Z\left(L D P-\frac{Z-E_{2}\left(X_{T}\right)\left(U_{\text {max }}-d\right)}{U_{\text {max }}(1-\alpha)-d}\right) \\
& \overline{I H_{3}}=\frac{Z^{2}}{2\left(U_{\max }-d\right)}+Z\left(E_{3}\left(X_{T}\right)-\frac{Z}{U_{\text {max }}-d}\right)+Z \cdot L D P
\end{aligned}
$$

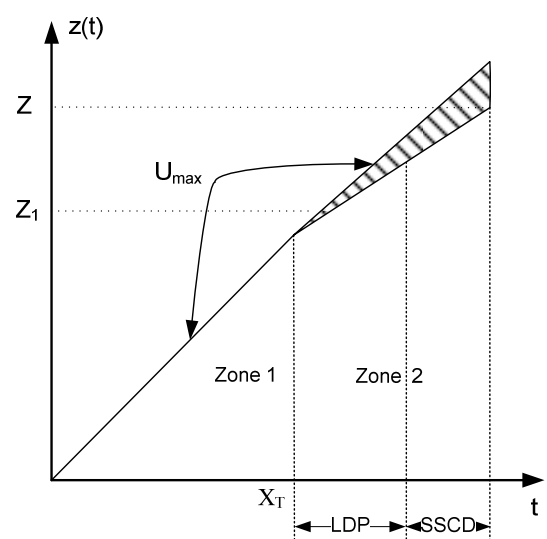

(a) Scenario 1

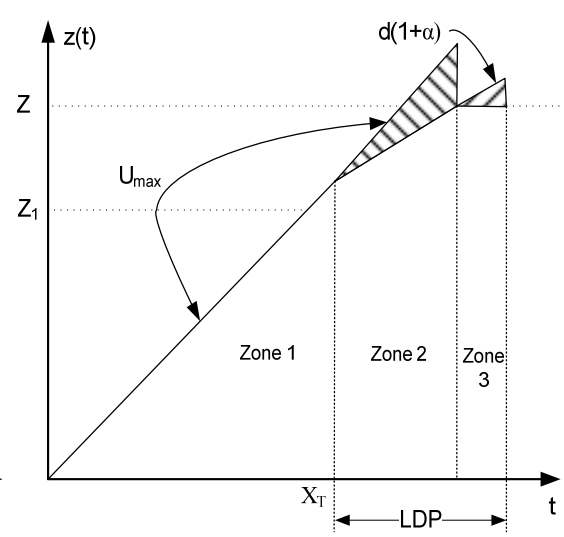

(b) Scenario 2

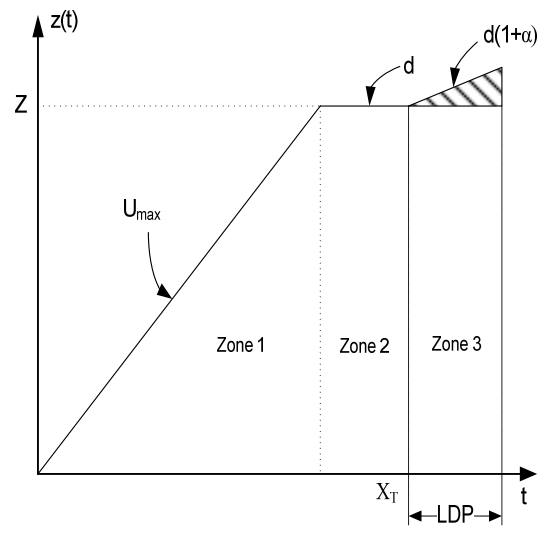

(c) Scenario 3

Figure 6 Inventory holding during production phase

\subsubsection{Expected cost of non-conforming items}

As soon as it shifts to the 'out-of-control' state, the manufacturing cell starts and continues to produce non-conforming items during the logistic delay period and until the security stock is built. The cost of non-conforming items includes the product raw material cost and the cell operating cost. Thus, the expected cost of non-conforming items produced by the manufacturing 
cell upon occurrence of Scenario 1 is determined by equation (34), where $C_{R M}$ is the raw material cost per item and $C_{M C O}$ is the manufacturing cell operating cost per time unit.

$$
C N C_{1}=\left(C_{R M} \alpha U_{\max }+C_{M C O} \alpha\right)(L D P+S S C D)
$$

The expected cost of non-conforming items produced by the manufacturing cell upon occurrence of Scenario 2 can be expressed by:

$$
C N C_{2}=\left(C_{R M} \alpha U_{\max }+C_{M C O} \alpha\right) P N C_{U_{\max }}+\left(C_{R M} \alpha d+C_{M C O} \frac{\alpha}{1+\alpha}\right)\left(L D P-P N C_{U_{\max }}\right)
$$

where $P N C_{U \max }$ is the expected period during which the manufacturing cell produces conforming and non-conforming items at its maximum production rate (Eq. 36) (i.e., time length of zone 2 (Fig. 6-b)).

$$
P N C_{U_{\max }}=\frac{Z-E_{2}\left(X_{T}\right)\left(U_{\max }-d\right)}{U_{\max }(1-\alpha)-d}
$$

Upon occurrence of Scenario 3, the expected cost of non-conforming items is given by equation (37), where $(\alpha /(1+\alpha))$ is the proportion of time during which the manufacturing cell produces non-conforming items.

$$
C N C_{3}=\left(C_{R M} \alpha d+C_{M C O}(\alpha /(1+\alpha))\right) L D P
$$

\subsection{Expected cost incurred during restoration phase}

The cost incurred during the restoration phase consists of the restoration cost, shortage cost and/or inventory holding cost.

Figures 2(a), 3(a), and 4(a) illustrate the situation where no shortage is observed during the restoration phase upon occurrence of Scenarios 1, 2, and 3, respectively. In this situation, an inventory surplus is noted, and the manufacturing cell remains non-operational until the complete depletion of the security stock. Thus, the cost incurred during the restoration phase in situations of surplus includes the cost for restoration $\left(C_{R}\right)$ to the 'as-good-as-new' 'in-control' state, and the inventory holding cost and can be expressed by:

$$
C R_{H}=C_{R}+C_{I} \frac{Z^{2}}{2 d}
$$

Figures 2(b), 3(b), and 4(b) illustrate the situation where a shortage situation is observed during restoration phase upon occurrence of Scenarios 1, 2, and 3, respectively. In this situation, the non-satisfied demand is assumed to be lost with a unit cost $C_{S}$, and the manufacturing cell starts producing conforming items immediately after a restoration action is undertaken. Therefore, the cost incurred during the restoration phase in situations of shortage is given by: 


$$
C R_{S}=C_{R}+C_{I} \frac{Z^{2}}{2 d}+C_{S} d\left(E_{S}\left(t_{r}\right)-\frac{Z}{d}\right)
$$

The problem is then to simultaneously determine the optimal values of the decision variables: the security stock capacity $\left(Z^{*}\right)$ and the preventive maintenance threshold age $\left(T^{*}\right)$ that minimize the overall expected cost $\left(C_{t}\right)$ incurred by the joint production-inventory control and age-based preventive maintenance policy.

\section{Numerical examples and sensitivity analysis}

We should recall that the overall expected cost $C_{t}$ is equal to the weighted expected cost per time unit incurred during the production and the restoration phases by the occurrence of Scenarios 1 , 2 , and 3, in cases of inventory surplus or shortage (Eq. 6). We then describe the optimization procedure developed to determine the joint optimal HPP/APM policy and its corresponding minimum overall expected cost $C_{t}{ }^{*}\left(Z^{*}, T^{*}\right)$. Following that, we present a numerical example to illustrate the applicability of the optimization procedure, and finally, we carry out sensitivity analyses to demonstrate the robustness of the proposed integrated model and to illustrate its important aspects.

\subsection{Optimization procedure}

Given the complexity of solving the proposed joint optimization model analytically, an iterative numerical optimization procedure has been developed with MATLAB software (Fig. 7). The optimization procedure allows a deduction of the optimal values of the decision variables $\left(Z^{*}, T^{*}\right)$ and their corresponding minimum overall expected cost $\left(C_{t}^{*}\right)$ for any operational and cost parameters of the considered manufacturing cell. 


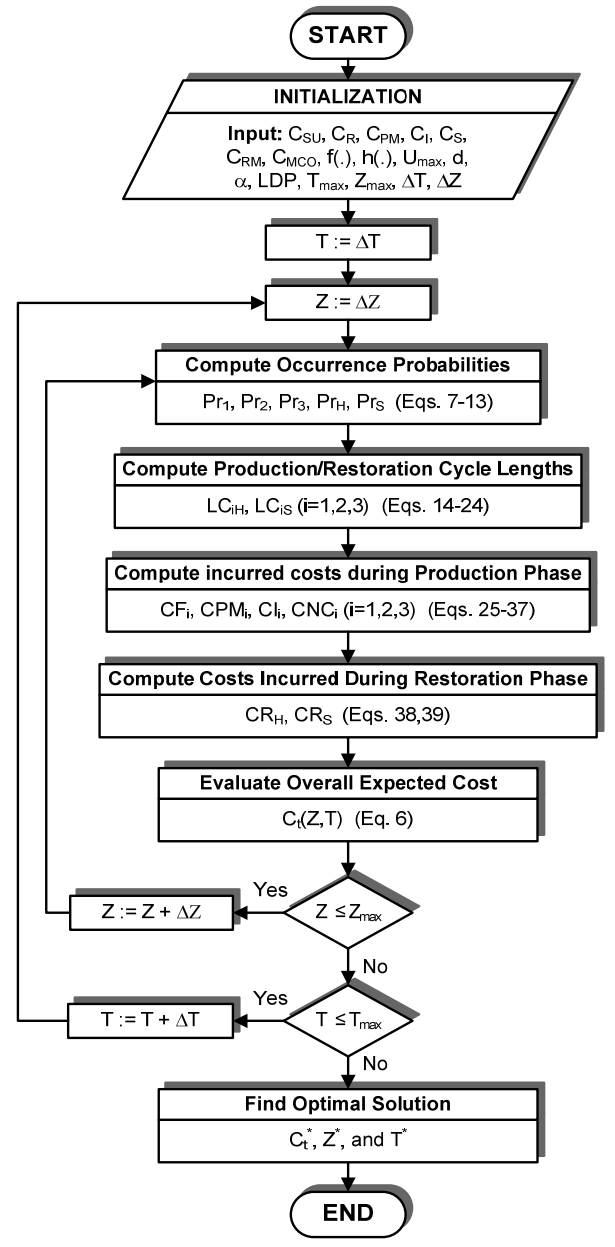

Figure 7 Iterative numerical procedure for joint optimal policy

The optimization procedure integrates an initialization module to read the input data $(f($.$) ,$ $\left.h(),. U_{\max }, d, \alpha, L D P, C_{S U}, C_{P M}, C_{R}, C_{I}, C_{S}, C_{R M}, C_{M C O}, \Delta Z, \Delta T\right) ; \Delta Z$ and $\Delta T$ are the increment values corresponding to the inventory level and the threshold age. The optimization procedure also includes other subroutines allowing the evaluation of the occurrence probability of possible scenarios, the expected cycle length for each scenario, the expected total cost incurred during the production phase for each scenario, and the expected total cost incurred during the restoration phase in a surplus or a shortage situation.

\subsection{Numerical example}

Consider a manufacturing cell having an automatic machine, manufacturing a single product type, and responding to a constant periodic demand of 20,160 units/month. The automatic machine can produce at a maximum rate equal to 32,400 units/month. The manufacturing cell is subject to a random alteration of its product quality. Statistics show that the 'in-control' state periods follow a Weibull distribution with shape and scale parameters 1.5 and 1, respectively; the mean life time of the manufacturing cell in the 'in-control' state is equal to 0.903 month. 
After a random operating period in the 'in-control' state, the manufacturing process may shift to the 'out-of-control' state, and start producing non-conforming items, at a rate equal to $1 \%$ of the actual production rate. Upon transition to the 'out-of-control' state, a preparation of the resources required for a restoration with a duration of 0.03 month is carried out. Restoration actions have random durations following a Gamma distribution with shape and scale parameters 2 and 40, respectively; the mean restoration time to the 'as-good-as-new' 'in-control' state is equal to 0.05 month.

The following costs are also chosen considering nevertheless a realistic context:

- $\quad$ Setup cost $\left(C_{S U}\right): 5000(\$)$

- $\quad$ Shortage cost $\left(C_{S}\right): 300$ (\$/product unit)

- $\quad$ Inventory holding cost $\left(C_{I}\right): 10(\$ /$ unit/month)

- $\quad$ Preventive maintenance cost $\left(C_{P M}\right): 750$ (\$/preventive maintenance action)

- $\quad$ Restoration cost $\left(C_{R}\right): 10,000$ (\$/restoration action)

- $\quad$ Raw material cost $\left(C_{R M}\right): 500$ (\$/product unit)

- $\quad$ Manufacturing cell operating cost $\left(C_{M C O}\right): 150,000$ (\$/month)

Figure 8-a (Fig. 8-b) shows the overall expected cost corresponding to the optimal value of $Z^{*}$ $\left(T^{*}\right)$ when varying the value of $T(Z) ; \Delta Z$ and $\Delta T$ are chosen to be equal to 10 product units and 0.01 month, respectively. Further, Figure 8 specifically shows the uniqueness of the optimal solution; this character of the function $C_{t}(Z, T)$ has also been observed for a wide range of parameter values of the manufacturing cell.

It can thus be deduced that the joint optimal HPP/APM policy aims to produce at the maximum rate until the security stock capacity of 2180 items is reached, after which the production rate is reduced to satisfy the demand rate. The joint optimal policy also dictates that a preventive maintenance action be performed as long as the restored or the maintained manufacturing cell is in the 'in-control' state - until a threshold age of 0.12 month is reached. According to these settings, the minimum overall cost incurred by the joint optimal policy is $\$ 42,405.60 / \mathrm{month}$.
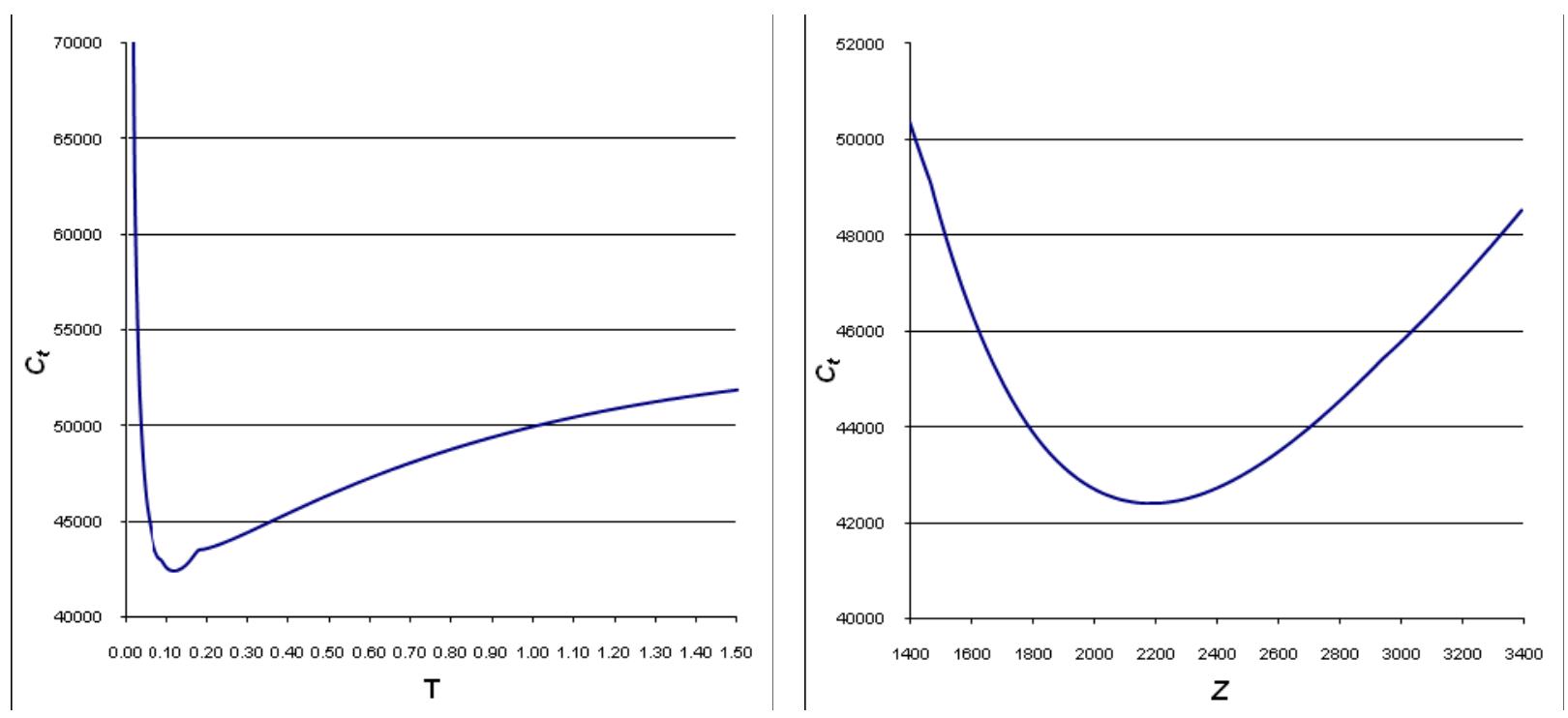

(a) $Z^{*}=2180$
(b) $T^{*}=0.12$

Figure 8 Overall incurred cost evolution with respect to $T$ and $Z$

The results clearly illustrate the trade-offs that exist between the preventive maintenance frequency and the overall incurred cost (Fig. 8-a). In fact, reducing the preventive maintenance frequency yields an increase in the overall incurred cost. With no preventive maintenance $(T \rightarrow \infty)$, the overall incurred cost rises to $\$ 49,423.30 /$ month (i.e., $16.55 \%$ relative cost increase), requiring a security stock hedging level of 2840 items. As expected, preventive maintenance has contributed in improving the overall performance of the manufacturing cell by reducing the incurred overall cost and by attenuating the shift frequency to the 'out-of-control' state. In this context, the proposed joint policy allows the assessment of the exact value of the optimal frequency at which preventive actions should be carried out $\left(T^{*}\right)$.

\subsection{Sensitivity analysis}

A set of experiments have also been considered to measure the sensitivity of the proposed joint optimal HPP/APM policy with respect to the model parameters. The goal is to demonstrate the efficiency and the robustness of the proposed model and to study the behaviour of the joint optimal policy when varying cost parameters, the proportion of non-conforming items, the mean logistic delay period, and the mean value of the restoration time distribution.

\subsubsection{Influence of cost parameters}

Table 1 presents 14 cost parameter configurations derived from the basic case (case 1) by changing them to higher and lower values, one at a time; the basic case is the manufacturing cell configuration considered in the previous numerical example. Table 1 highlights the consistency between the variation of each cost parameter and the optimal decision variables and cost. Their variations are examined and compared with the basic case as follows:

- Variation of the restoration cost $C_{R}$ (cases 2 and 3): When the restoration cost increases (case 3), the joint control policy gives preference to preventive maintenance, and as a result, the preventive maintenance age threshold $\left(T^{*}\right)$ decreases. In this situation, the average number of failures decreases, resulting in fewer inventory shortages. Consequently, the inventory control requires a lower hedging point $Z^{*}$. An increase in the restoration cost leads both to a decrease in the inventory cost and to an increase in the maintenance cost, but the overall cost increases. A decrease in the restoration cost has the opposite effects (case 2).

- Variation of the preventive maintenance cost $C_{P M}$ (cases 4 and 5): A variation of the preventive maintenance cost has the opposite effect when compared with the variation of the restoration cost. Indeed, they both affect the optimal balance between preventive maintenance and restoration.

- Variation of the setup cost $C_{S U}$ (cases 6 and 7): A variation of the setup cost has the same (opposite) effect when compared with the variation of the restoration (preventive maintenance) cost. 
- Variation of the inventory holding cost $C_{I}$ (cases 8 and 9): When the holding cost increases (case 9), the joint optimal policy reacts by lowering the hedging point $Z^{*}$. The average inventory level will then decrease, while the risk of shortage increases. The maintenance control policy then adapts to avoid breakdowns by lowering the preventive maintenance age threshold $\left(T^{*}\right)$. The total cost increases in response to an increase in the holding cost. Note that a decrease in the holding cost has the opposite effects (case 8).

Table 1 Sensitivity analysis for different cost parameters

\begin{tabular}{ccccccccccc}
\hline Case number & $C_{R}$ & $C_{P M}$ & $C_{S U}$ & $C_{I}$ & $C_{S}$ & $C_{R M}$ & $C_{M C O}$ & $Z^{*}$ & $T^{*}$ & $C_{t}^{*}$ \\
\hline $\mathbf{1}$ & $\mathbf{1 0 , 0 0 0}$ & $\mathbf{7 5 0}$ & $\mathbf{5 0 0 0}$ & $\mathbf{1 0}$ & $\mathbf{3 0 0}$ & $\mathbf{5 0 0}$ & $\mathbf{1 5 0 , 0 0 0}$ & $\mathbf{2 1 8 0}$ & $\mathbf{0 . 1 2}$ & $\mathbf{4 2 , 4 0 6}$ \\
2 & $\mathbf{5 0 0 0}$ & 750 & 5000 & 10 & 300 & 500 & 150,000 & 2240 & 0.14 & 39,959 \\
3 & $\mathbf{1 5 , 0 0 0}$ & 750 & 5000 & 10 & 300 & 500 & 150,000 & 2150 & 0.11 & 44,769 \\
4 & 10,000 & $\mathbf{5 0 0}$ & 5000 & 10 & 300 & 500 & 150,000 & 2050 & 0.07 & 40,265 \\
5 & 10,000 & $\mathbf{1 0 0 0}$ & 5000 & 10 & 300 & 500 & 150,000 & 2250 & 0.14 & 44,065 \\
6 & 10,000 & 750 & $\mathbf{1 0 0 0}$ & 10 & 300 & 500 & 150,000 & 2210 & 0.13 & 40,454 \\
7 & 10,000 & 750 & $\mathbf{1 0 , 0 0 0}$ & 10 & 300 & 500 & 150,000 & 2150 & 0.11 & 44,769 \\
8 & 10,000 & 750 & 5000 & $\mathbf{5}$ & 300 & 500 & 150,000 & 2600 & 0.14 & 31,451 \\
9 & 10,000 & 750 & 5000 & $\mathbf{1 5}$ & 300 & 500 & 150,000 & 1920 & 0.11 & 51,953 \\
10 & 10,000 & 750 & 5000 & 10 & $\mathbf{2 0 0}$ & 500 & 150,000 & 1900 & 0.11 & 40,047 \\
11 & 10,000 & 750 & 5000 & 10 & $\mathbf{4 0 0}$ & 500 & 150,000 & 2390 & 0.13 & 44,046 \\
12 & 10,000 & 750 & 5000 & 10 & 300 & $\mathbf{3 0 0}$ & 150,000 & 2250 & 0.13 & 40,932 \\
13 & 10,000 & 750 & 5000 & 10 & 300 & $\mathbf{7 0 0}$ & 150,000 & 2120 & 0.11 & 43,811 \\
14 & 10,000 & 750 & 5000 & 10 & 300 & 500 & $\mathbf{5 0 , 0 0 0}$ & 2190 & 0.12 & 42,380 \\
15 & 10,000 & 750 & 5000 & 10 & 300 & 500 & $\mathbf{4 0 0 , 0 0 0}$ & 2180 & 0.12 & 42,469 \\
\hline
\end{tabular}

- Variation of the shortage cost $C_{S}$ (cases 10 and 11): A variation of the shortage cost has the opposite effect when compared with the variation of the inventory holding cost. The system tolerance for shortage risk is affected by any variations of the shortage cost. The joint optimal policy gives preference to increased security stock capacity when the shortage cost increases (case 11). As a result, the hedging point level $Z^{*}$ and the preventive maintenance age threshold $\left(T^{*}\right)$ increase; also the overall incurred cost increases. Note that a decrease in the shortage cost has the opposite effects (case 10).

- Variation of the raw material cost $C_{R M}$ (cases 12 and 13): An increase in raw material costs implies an increase in the total cost of non-conforming items produced by the manufacturing cell. To reduce the total cost of non-conforming items, the inventory level should be lowered and preventive actions performed more frequently when the raw material cost increases (case 13). Therefore, the hedging point level $Z^{*}$ and the preventive maintenance age threshold $\left(T^{*}\right)$ decrease, while the overall incurred cost increases. Note that a decrease in the raw material cost has the opposite effects (case 12).

- Variation of the manufacturing cell operating $\operatorname{cost} C_{M C O}$ (cases 14 and 15): A variation of the operating cost of the manufacturing cell has the same effect when compared with the variation of the raw material cost, but with a lower impact.

\subsubsection{Influence of the percentage of non-conforming items, the preparation time for restoration, and the mean value of the restoration time distribution}


Table 2 presents six configurations of the manufacturing cell derived from the basic case (case 1) by changing the percentage of non-conforming items, the preparation time for restoration, and the mean time of restoration actions, to higher and lower values, one at a time. The first observation from Table 2 is that the optimum parameters of the joint HPP/APM policy evolve in the same direction and with the same magnitude in response to any variation in related quality and restoration parameters. Their variations are examined and compared with the basic case as follows:

- Variation of the percentage of non-conforming items $\alpha$ (cases 2 and 3): When the fraction of non-conforming items increases (case 3), the joint control policy gives preference to preventive maintenance, and as a result, the preventive maintenance age threshold $\left(T^{*}\right)$ decreases. In this situation, the average number of failures decreases, resulting in fewer inventory shortages. Accordingly, the inventory control requires a lower hedging point $Z^{*}$. Increasing the percentage of non-conforming items leads to an increase in the non-conforming incurred cost, and thus to an increase in the overall cost. A decrease in the percentage of nonconforming items has the opposite effects (case 2).

Table 2 Sensitivity analysis for quality and restoration parameters

\begin{tabular}{ccccccc}
\hline Case number & $\alpha$ & $L D P$ & $M T T R$ & $Z^{*}$ & $T^{*}$ & $C_{t}^{*}$ \\
\hline $\mathbf{1}$ & $\mathbf{0 . 0 1}$ & $\mathbf{0 . 0 3}$ & $\mathbf{0 . 0 5}$ & $\mathbf{2 1 8 0}$ & $\mathbf{0 . 1 2}$ & $\mathbf{4 2 , 4 0 6}$ \\
2 & $\mathbf{0 . 0 0 5}$ & 0.03 & 0.05 & 2260 & 0.13 & 40,584 \\
3 & $\mathbf{0 . 0 2}$ & 0.03 & 0.05 & 2040 & 0.10 & 45,753 \\
4 & 0.01 & $\mathbf{0 . 0 1}$ & 0.05 & 2190 & 0.12 & 41,857 \\
5 & 0.01 & $\mathbf{0 . 1}$ & 0.05 & 2120 & 0.11 & 44,171 \\
6 & 0.01 & 0.03 & $\mathbf{0 . 0 2 5}$ & 1080 & 0.17 & 28,340 \\
7 & 0.01 & 0.03 & $\mathbf{0 . 1}$ & 4340 & 0.10 & 66,729 \\
\hline
\end{tabular}

- Variation of the preparation time for restoration LDP (cases 4 and 5): A variation of the logistic delay period has the same effect when compared with the variation of the percentage of non-conforming items. In fact, the logistic delay period and the percentage of nonconforming items are the main parameters affecting the total cost incurred by producing nonconforming items. However, we note that the variation of $L D P$ has a lower impact than that of the percentage of non-conforming items.

- Variation of the mean time to restoration MTTR (cases 6 and 7): The risk of shortage is essentially affected by the mean time to restore the manufacturing cell. In fact, an increase in the MTTR implies a higher inventory level and more frequent preventive actions in order to avoid shortages (case 7 ). Therefore, the hedging point level $Z^{*}$ increases, while the preventive maintenance age threshold $\left(T^{*}\right)$ decreases. An increase in the mean time to restore the manufacturing cell also implies an increase in the overall incurred cost. It can be noted that a decrease in the mean value of the restoration actions has the opposite effects (case 6).

\section{Conclusions}

This paper presents an integrated strategy for the joint optimization of the production-inventory control and the preventive maintenance of an imperfect process manufacturing cell responding to 
a constant and continuous demand. The production-inventory control policy is based on the hedging point policy which allows finished product security stock to be built in order to hedge against eventual shortages during system restoration periods when the manufacturing process shifts to the 'out-of-control' state. An age-based preventive maintenance policy has also been considered in order to reduce the shift rate to the 'out-of-control' state.

A mathematical model has been proposed for manufacturing cells having general distributions of restoration periods and the shifting times to the 'out-of-control' state. The proposed model takes into account all possible scenarios that can occur, depending on the instant at which the manufacturing cell shifts to the 'out-of-control' state. This directly affects the costs incurred during the production phase and the length of the production/restoration cycle, providing the underlying link between production, maintenance, and quality aspects of manufacturing systems.

A numerical procedure is also developed to solve the complex mathematical model and to generate the joint optimal strategy described by the security stock hedging level $\left(Z^{*}\right)$ and the age threshold $\left(T^{*}\right)$ at which preventive actions should be performed. The joint optimal strategy minimizes the overall expected cost per time unit, including setup, preventive maintenance, restoration, inventory holding, shortage, and non-conforming item costs.

The numerical resolution procedure was first tested on a base case example of a manufacturing cell with realistic operational, maintenance, and cost parameters. The results show that the preventive maintenance policy contributes to a reduction of the overall incurred cost. Sensitivity analyses based on several experiments have also been carried out to show the effectiveness and the robustness of the proposed integrated model. In fact, the results show that the joint optimal policy is generally sensitive to the cost, the production/maintenance, and the quality parameters of the manufacturing cell considered.

This article should stimulate further research on joint production control/preventive maintenance policies. We suggest that other preventive maintenance strategies, as bloc replacement policies, should be investigated. In the other hand, this research should be extended to develop analytical models for more complicated systems, such as failure prone manufacturing systems and products subject to perishability phenomenon.

\section{References}

Akella, R., Choong, Y., Gershwin, S.B., 1984. Performance of hierarchical production scheduling policy. IEEE Transactions on Components, Hybrids, and Manufacturing Technology 7, 225-240.

Akella, R., Kumar, P.R., 1986. Optimal control of production rate in a failure prone manufacturing system. IEEE Transactions on Automatic Control 31, 116-126.

Barlow, R.E., Hunter, L., 1960. Optimal preventive maintenance policies. Operations Research 8, 90-100.

Barlow, R.E., Proschan, F., 1965. Mathematical theory of reliability. Wiley, New York.

Ben-Daya, M., 1999. Integrated production maintenance and quality model for imperfect processes. IIE Transactions 31, 491-501.

Ben-Daya, M., 2002. The economic production lot-sizing problem with imperfect production processes and imperfect maintenance. International Journal Production Economics 76, 257-264. 
Ben-Daya, M., Noman, S.M., 2008. Joint optimal ordering and inspection policies for deterministic demand. European Journal of Operational Research 185, 159-169.

Ben-Daya, M., Noman, S.M., Hariga, M., 2006. Integrated inventory and inspection policies for stochastic demand. Computers and Operations Research 33, 1625-1638.

Ben-Daya, M., Rahim, M.A., 2000. Effect of maintenance on the economic design of x-control chart. European Journal of Operational Research 120, 131-143.

Berthaut, F., Gharbi, A., Dhouib, K., 2011. Joint modified block replacement and production/inventory control policy for a failure-prone manufacturing cell. OMEGA 39, 642-654.

Chelbi, A., Ait-Kadi, D., 2004. Analysis of a production/inventory system with randomly failing production unit submitted to regular preventive maintenance. European Journal of Operational Research 156, 712-718.

Chelbi, A., Ait-Kadi, D., Radhoui, M., 2008. An Integrated production and maintenance model for one failure prone machine-finite capacity buffer system for perishable products with constant demand. International Journal of Production Research 46, 5427-5440.

Chelbi, A., Rezg, N., Radhoui, M., 2008. Simultaneous determination of production lot size and preventive maintenance schedule for unreliable production system. Journal of Quality in Maintenance 14, 161-176.

Feng, Y., Xiao, B., 2002. Optimal Threshold Control in Discrete Failure-Prone Manufacturing Systems. IEEE Transactions on Automatic Control 47, 1167-1174.

Gharbi, A., Kenné, J.P., Beit, M., 2007. Optimal safety stocks and preventive maintenance periods in unreliable manufacturing systems. International Journal of Production Economics 107, 422-434.

Goyal, S.K., Cardenas-Barron, L.E., 2002. Note on: Economic production quantity model for items with imperfect quality - a practical approach. International Journal of Production Economics 77, 85-87.

Groenevelt, H., Pintelon, L., Siedmann, A., 1992. A Production Lot Sizing with machine breakdown. Management Science 38, 104-123.

Hariga, M., Ben-Daya, M., 1998. The economic manufacturing lot sizing problem with imperfect manufacturing processes: bounds and optimal solutions. Naval Research Logistics 45, 423-433.

Kenné, J.P., Gharbi, A., Beit, M., 2007. Age-dependent production planning and maintenance strategies in unreliable manufacturing systems with lost sale. European Journal of Operational Research 178, 408-420.

Ki Ling, C., Hausman, W.H., 1997. Joint determination of preventive maintenance and safety stocks in an unreliable production environment. Naval Research Logistics 44, 257-272.

Kimemia, J.G., Gerschwin, S.B., 1983. An algorithm for the computer control of production in flexible manufacturing systems. IIE Transactions 15, 353-362.

Lee, H.L., Rosenblatt, M.J., 1987. Simultaneous determination of production cycle and inspection schedules in a production system. Management Science 33, 1125-36.

Porteus, E.L., 1986. Optimal lot sizing, process quality improvement and setup cost reduction. Operations Research 34, 137-44.

Radhoui, M., Rezg, N., Chelbi, A., 2009. Integrated model of preventive maintenance, quality control and buffer sizing for unreliable and imperfect production systems. International Journal Production Research 47, 389-402.

Rezg, N., Dellagi, S., Chelbi, A., 2008. Joint optimal inventory control and preventive maintenance policy. International Journal of Production Research 46, 5349-5365.

Salameh, M.K., Ghattas, R.E., 2001. Optimal just-in-time buffer inventory for regular preventive maintenance. International Journal of Production Economics 74, 157-161.

Tadashi, D., Hiroyuki, O., Shunji, O., 2001. Optimal control of preventive maintenance schedule and safety stocks in an unreliable manufacturing environment. International Journal of Production Economics 74, 147-155.

Wee, H.M., Yu, J., Chen, M.C., 2007. Optimal inventory model for items with imperfect quality and shortage backordering. OMEGA 35, 7-11. 